\title{
Comparison of Abdominal And Vaginal Hysterectomy: A Comparative Clinical Study At A Tertiary Hospital Of Southern Part of Bangladesh
}

\author{
Dr. Md. Akbar Hossain ${ }^{1}$,Dr. Kaniz Fatema ${ }^{2}$,Dr. Samorendra Sarker ${ }^{3}$, \\ Dr. Sonali Rani Datta ${ }^{4}$,Dr. Selina Parvin ${ }^{5}$, \\ ${ }^{I}$ Assistant Professor,Department of Gynaecology and Obstetrics, Sher-E-Bangla Medical College, \\ Barisal, Bangladesh. \\ ${ }^{2}$ Residential Surgeon, Sher-E-Bangla Medical College Hospital, Barisal, Bangladesh. \\ ${ }^{3}$ Assistant Professor, Department of Gynaecology and Obstetrics, Sher-E-Bangla Medical College, \\ Barisal, Bangladesh. \\ ${ }^{4}$ Junior Consultant-Gynae, Model Family Planning Clinic, Sher-E-Bangla Medical College, \\ Barisal, Bangladesh. \\ ${ }^{5}$ Professor, Department of Gynaecology and Obstetrics, Sher-E-Bangla Medical College, Barisal, \\ Bangladesh.
}

\begin{abstract}
Introduction: Hysterectomy is indicated in several common gynecologic problems and is one of the commonly performed operations in many hospitals of Bangladesh. Though Hysterectomy is a reasonably safe operative procedure but at times minor to major complications may occur. Current study was undertaken to compare the feasibility and safety of abdominal hysterectomy $(\mathrm{AH})$ and vaginal hysterectomy $(\mathrm{VH})$ procedures in the treatment of benign uterine diseases, and to determine the outcomes of both procedures.

Objectives: To compare outcomes of vaginal and abdominal hysterectomy procedures in women with benign gynaecological

Diseases. Methods: This was a prospective study of outcomes of consecutive patients who underwent AH or VH for benign gynaecological diseases. Patient characteristics before, during, and after the operations were reviewed. Patients were followed up for three months to evaluate postoperative complications.

Results: This study included a total of 305 patients. 199 patients underwent $\mathrm{AH}$ and 106 patients underwent VH. Baseline characteristics were similar between the two groups. Mean operative time was $95.78 \pm 18.46$ minutes for AH group and $76.26 \pm 19.24$ minutes for VH group $(p<0.006)$. Mean hospital stay was $5.32 \pm 0.67$ days for $A H$ group and $4.08 \pm 0.19$ days for $V H$ group with $p$-value $<0.047$. There was a significant lesser total operation cost in VH group than AH group (VH: $12058 \pm 386$ BDT,

AH: $14275 \pm 276$ BDT; $P<0.05)$. Furthermore there was no wound infection; paralytic ileus and no need to reopening any patient in case of $\mathrm{VH}$ group compared to $\mathrm{AH}$ group.

Conclusion: This study showed that vaginal hysterectomy was associated with less intraoperative complications and postoperative morbidities and complications as compared to abdominal hysterectomy.
\end{abstract}

Keywords: Hysterectomy, abdominal hysterectomy, vaginal hysterectomy, indications, postoperative outcome, post-operative complications.

\section{Introduction}

The term hysterectomy originates from two Greek words: "hystero" which means uterus and "ectomy" which means resection removal from the human body ${ }^{1}$. This surgical procedure is indicated in several common gynecologic problems and is one of the commonly performed operations in many hospitals of Bangladesh. Hysterectomy is either total or subtotal, with or without the adnexae and depended on the way performed: abdominal, vaginal and laparoscopic or laparoscopic assisted vaginal hysterectomy. Historically the first vaginal hysterectomy was performed by Conrad Langenbeck in 1813, the first subtotal abdominal hysterectomy by Walter Burnham in 1853, the first elective abdominal hysterectomy by Clay and Koeberle in 1863, and the first laparoscopic hysterectomy by Harry Reich in $1988^{1}$. It is stated that nine out of every ten hysterectomies are performed for non-malignant diseases ${ }^{2}$.

Currently there are three main types of hysterectomy operations in practice for benign diseasesabdominal hysterectomy $(\mathrm{AH})$, vaginal hysterectomy $(\mathrm{VH})$ and laparoscopic hysterectomy $(\mathrm{LH})$. AH remains the predominant method of uterine removal. This route is used for malignancies, bulky uteri or when there are adhesions and removal of uterus is not possible through VH. Currently it exceeds VH by a ratio of 1:1 to 6:1 across North America ${ }^{3}$. VH was initially only used for prolapse, but its indications are now increasing. VH is 
accepted as less invasive than $\mathrm{AH}$ and there are reports of its preferential use as it has many advantages over $\mathrm{AH}$ ${ }^{4-6}$. LH requires greater surgical skills and takes longer than the other two routes. There is greater danger of bladder or ureteric injury. Indications, of hysterectomy include Leiomyomas, endometriosis, uterovaginal (UV) prolapse (pelvic relaxation), pelvic inflammatory disease (PID), endometrial hyperplasia, dysfunctional/abnormal uterine bleeding (DUB), menorrhagia, dysmenorrhoea or pelvic pain associated with significant pelvic disease, intractable postpartum haemorrhage, ruptured tubo-ovarian abscesses, endometrial hyperplasia with atypia and malignancies such as cervical intraepithelial neoplasia or invasive disease ${ }^{7,8}$. Surgical technique for vaginal myomectomy has now been described by posterior ${ }^{9}$ as well as anterior route, ${ }^{10}$ even for fibroids weighing up to $1,600 \mathrm{~g}{ }^{11}$. For DUB, hysterectomy is last treatment option for women who have completed childbearing, do not tolerate medical treatment or have atypical endometrial hyperplasia ${ }^{12}$. The selection of cases for $\mathrm{VH}$ or $\mathrm{AH}$ depends upon many clinical variables singly or in combination. These include pelvic anatomy, uterine size, adnexal disease, gastrointestinal complaints, urological disorders, (cystocele/prolapse of the urethrovesical angle, rectocoele, enterocoele), heart or lung disease, body mass index, parity, previous tubal ligation or caesarean section ${ }^{13}$. Hysterectomy is a reasonably safe, common, and routine surgical procedure which rarely leads to peri-operative death ${ }^{2}$. Overall mortality rates for AH or VH are $0.1-$ $0.2 \%{ }^{14}$. It is not associated with long-term risk of death ${ }^{2}$. Minor complications, including postoperative infection, fever, wound haematoma or separation, occur in about $25 \%$ of patients, and major complications, including blood transfusion and injury to bowel, bladder, or ureter, occur in $5 \%$ to $14 \%$ of patients ${ }^{15}$. The most serious postoperative complication is haemorrhage $(0.2-2 \%){ }^{16}$. About $10 \%$ patients are expected to have postoperative febrile morbidity and infection ${ }^{8}$. The urinary bladder may be injured in $2.9 \%$ of all hysterectomies. Ureteral injury occurs in $0.7-1.8 \%$ of $\mathrm{AH}$ and $0-0.1 \%$ of $\mathrm{VH}^{17}$. Damage to the bowel is quite uncommon, particularly with $\mathrm{VH}^{18}$. About $80 \%$ injuries occur at the junction of ureter and uterine artery ${ }^{19}$. Younger women undergoing hysterectomy for symptomatic fibroids (especially LAVH) are at most risk of experiencing severe operative and postoperative complications ${ }^{20}$. Women might be at higher risk of depression, anxiety and psychosexual problems following hysterectomy ${ }^{21}$. This study was undertaken to compare the feasibility and safety of $\mathrm{VH}$ and $\mathrm{AH}$ procedures in the treatment of benign uterine diseases, and to determine the outcomes of both procedures.

\section{Materials And Methods}

This is a prospective study which was carried out in Sher-E-Bangla Medical College Hospital, Barisal; Bangladesh over a period of five (5) years from January 2011 to December 2015.The study included 305 female patients who underwent $\mathrm{AH}$ or VH at the Department of Obstetrics and Gynaecology. Patients were selected from OPD, by taking detailed medical history, general physical and systemic examination; ultrasound and biopsy examinations. All cases were diagnosed with uterine benign diseases, including uterine fibroids, adenomyosis, dysfunctional uterine bleeding, uterovaginal prolapse, cervical intraepithelial neoplasia (CIN) III and endometrial hyperplasia. Finally diagnoses were confirmed by biopsy examinations. All patients were followed up for at least 3 months. The confounding variables were controlled by strictly following the inclusion and exclusion criteria.

Inclusion criteria were: 1) benign uterine diseases such as uterine fibroids, adenomyosis, and CIN; 2) gynecological symptoms that justified total hysterectomy; 3) indicated for either $\mathrm{AH}$ or $\mathrm{VH}$; 4) patients without fertility requirement; 5) patients with the follow-up period of more than 3 months; and 6) patients who gave their informed consent to participate.

Exclusion criteria were: 1) subjects with morbid obesity (BMI>30); 2) pelvic malignancy; 3) cardiac diseases; 4) bronchial asthma; 5) hypertension 6) nulliparity; 7) previous caesarean delivery; 8) subjects requiring bilateral salpingo-oophorectomy; 9) patients with the follow-up period of less than 3 months; 10) pelvic inflammatory disease; 11) endometriosis; 12) those whose route of hysterectomy was needed to change during operation and 13) patients with fertility requirement.

The gynecologists allocated the patient to either $\mathrm{AH}$ or $\mathrm{VH}$ according to preferred clinical grounds. Patients were selected for AH with the following clinical criteria: 1) fixed uterus or no uterine descent; 2) unmarried women; and 3) vaginal stenosis. Patients were selected for VH with the following clinical criteria: 1) freely mobile uterus; and 2) more than one vaginal delivery.Routine systemic, gynaecological, and cervical cytological examinations were performed for all patients who underwent total hysterectomies. Fractional curettage was performed to exclude gynaecological malignancies. Patient characteristics [e.g., age, weight, body mass index (BMI)] were recorded. Informed written consent was taken from them by explaining risks and benefits associated with the procedure. Approval of ethical committee was also taken. All the procedures were performed by the same surgeon.

All patients underwent spinal anaesthesia (SA).Perioperative outcomes were measured in terms of operative time in minutes, urinary bladder or ureteric injury and primary haemorrhage. Post-operative outcomes were measured in terms of post-operative analgesia, postoperative recovery time, pyrexia, wound infection, 
urinary tract infection, hospital stay in days, secondary haemorrhage, estimated cost, readmission, re-opening and mortality. The length of the operative time in minutes was recorded from the first surgical incision to the time at which all wounds were closed and dressed. Blood loss was estimated by measurement of aspirated blood and weighing of swabs. Every patient had haemoglobin estimation pre-operatively and on the third postoperative day.

All the patients were prescribed the same broad spectrum antibiotics and an identical regimen of postoperative analgesia. Post-operative temperatures were recorded 4 hourly and any patient having temperature more than $37.5^{\circ} \mathrm{C}$ were investigated. The length of the time (days) from the morning of the first post-operative day up to and including the day of the discharge was recorded. Apyrexial, fully ambulated patient requiring no further analgesia were considered fit for discharge.Statistical analyses were performed using the STATA package version 11. The means and or percentages for the different variables were calculated. Comparisons were done between $\mathrm{AH}$ and $\mathrm{VH}$ groups. Statistical significance was ascertained using the $\mathrm{z}$ test. A p value $<0.05$ was considered statistically significant.

\section{Results}

A total of 305 patients were included in the study. Out of 305 hysterectomies 109 (35.74\%) were performed for uterine leiomyomas, 67 (21.97\%) for UV-prolapsed, 55 (18.03\%) for adenomyosis, 40 (13.12\%) for dysfunctional uterine bleeding (DUB) and only 17 (5.57\%) for each of endometrial hyperplasia and cervical intraepithelial neoplasia (CIN). Breakdown of indications according to type of hysterectomy (AH vs $\mathrm{VH}$ ) have been given in Table-1.

Table-1. Indications of hysterectomy $(n=305)$

\begin{tabular}{|l|l|l|l|}
\hline Indications & $\begin{array}{l}\text { AH } \\
(\mathrm{n}=199)\end{array}$ & $\begin{array}{l}\text { VH } \\
(\mathrm{n}=106)\end{array}$ & $\begin{array}{l}\text { Total } \\
(\mathrm{n}=305)\end{array}$ \\
\hline Leiomyoma & $97(48.74 \%)$ & $12(11.32 \%)$ & $109(35.74 \%)$ \\
\hline Adenomyosis & $45(22.61 \%)$ & $10(9.43 \%)$ & $55(18.03 \%)$ \\
\hline Endometrial hyperplasia & $12(6.03 \%)$ & $05(4.72 \%)$ & $17(5.57 \%)$ \\
\hline Cervical intraepithelial neoplasia (CIN) & $11(5.53 \%)$ & $06(5.66 \%)$ & $17(5.57 \%)$ \\
\hline Dysfunctional uterine bleeding (DUB) & $31(15.58 \%)$ & $09(8.49 \%)$ & $40(13.12 \%)$ \\
\hline Uterovaginal prolapsed & $03(1.51 \%)$ & $64(60.38 \%)$ & $67(21.97 \%)$ \\
\hline Total & $199(100 \%)$ & $106(100 \%)$ & $305(100 \%)$ \\
\hline
\end{tabular}

Table-2 outlines patient characteristics, frequency of peri-operative events including blood loss, mean fall in haemoglobin level and comparison of length of hospital stay and cost. There was no significant difference in patient characteristics between the two groups. There were no intraoperative complications such as bladder, rectum or urethra injuries in any groups. Compared with $\mathrm{AH}, \mathrm{VH}$ was associated with a significant shorter mean operation time (VH: 76.26 $\pm 19.24 \mathrm{~min}, \mathrm{AH}$ : $95.78 \pm 18.46 \mathrm{~min} ; \mathrm{P}<0.05)$ and less mean intraoperative blood loss (VH: $86.50 \pm 11.26 \mathrm{ml}, \mathrm{AH}: 160.72 \pm 34.35 \mathrm{ml} ; P<0.05$ ). There was a significant shorter mean hospital stay in VH group than AH group (VH: $4.08 \pm 0.19$ days, AH: $5.32 \pm 0.67$ days; $P<0.05$ ) and a significant lesser total operation cost in VH group than AH group (VH: $12058 \pm 386$ BDT, AH: $14275 \pm 276$ BDT; $P<0.05$ ).

Table-2. Comparison of patient characteristics, peri- and post-operative events $(n=305)$

\begin{tabular}{|l|l|l|l|}
\hline \multirow{2}{*}{ Variable } & \multicolumn{2}{|c|}{ Mean \pm SD } & \multirow{2}{*}{$\boldsymbol{p}$-value } \\
\cline { 2 - 3 } & $\begin{array}{l}\mathrm{AH} \\
(n=199)\end{array}$ & $\begin{array}{l}\mathrm{VH} \\
(n=106)\end{array}$ & \\
\hline Age (years) & $48 \pm 4.66$ & $52 \pm 6.8$ & $\mathrm{NS}$ \\
\hline Weight (kg) & $56.74 \pm 5.79$ & $59.45 \pm 7.26$ & $\mathrm{NS}$ \\
\hline Height (cm) & $160.32 \pm 3.12$ & $154.76 \pm 5.49$ & $\mathrm{NS}$ \\
\hline BMI & $26.30 \pm 2.44$ & $27.74 \pm 2.45$ & $\mathrm{NS}$ \\
\hline Parity & $3.56 \pm 1.54$ & $4.04 \pm 1.48$ & $\mathrm{NS}$ \\
\hline Preoperative haemoglobin (g/dl) & $10.96 \pm 1.22$ & $11.14 \pm 1.01$ & $\mathrm{NS}$ \\
\hline Duration of operation (min) & $95.78 \pm 18.46$ & $76.26 \pm 19.24$ & 0.006 \\
\hline Blood loss (ml) & $160.72 \pm 34.35$ & $86.50 \pm 11.26$ & 0.048 \\
\hline Drop in Haemoglobin & $1.03 \pm 0.47$ & $0.79 \pm 0.86$ & 0.36 \\
\hline Hospital stay (days) & $5.32 \pm 0.67$ & $4.08 \pm 0.19$ & 0.047 \\
\hline Total cost (BDT) & $14275 \pm 276$ & $12058 \pm 386$ & 0.008 \\
\hline
\end{tabular}

Comparison regarding postoperative complications between $\mathrm{AH}$ and $\mathrm{VH}$ groups are shown in Table-3. There was no pyrexia, wound infection, postoperative paralytic ileus and need of re-opening in VH group. A significant number of patients need re-admission in AH group in comparison with $\mathrm{VH}$ group (VH: 1 (2.5\%), AH: $9(22.5 \%) ; P<0.05)$. 
Table-3: Post-operative complications $(n=305)$

\begin{tabular}{|l|l|l|l|}
\hline Variable & AH $(n=199)$ & VH $(n=106)$ & $p$-value \\
\hline Pyrexia & $2(5.0 \%)$ & 0 & 0.1518 \\
\hline Secondary haemorrhage & $5(12.5 \%)$ & $2(5 \%)$ & 0.61 \\
\hline Wound infection & $6(15 \%)$ & $0(0 \%)$ & 0.0399 \\
\hline Paralytic ileus & $2(5.26 \%)$ & $0(0 \%)$ & 0.1518 \\
\hline Vaginal vault hematoma/infection & $1(2.63 \%)$ & $3(7.89 \%)$ & 0.3042 \\
\hline Bleeding requiring transfusion & $3(7.5 \%)$ & $1(2.5 \%)$ & 0.432 \\
\hline Re-admission & $9(22.5 \%)$ & $1(2.5 \%)$ & 0.014 \\
\hline Re-opening & $2(5 \%)$ & 0 & 0.1518 \\
\hline
\end{tabular}

\section{Discussion}

Hysterectomy, the most common major surgical procedure for gynaecological conditions, is used for both malignant diseases and benign conditions such as fibroids, endometrial hyperplasia, adenomyosis, endometriosis, uterine prolapse, dysfunctional uterine bleeding, and cervical intraepithelial neoplasia ${ }^{22}$. There are many approaches to hysterectomy for benign diseases, including $\mathrm{AH}, \mathrm{VH}$, laparoscopic assisted vaginal hysterectomy (LAVH), total laparoscopic hysterectomy (TLH), and subtotal laparoscopic hysterectomy. With the constant modernization of minimally invasive concepts in obstetrics and gynaecology, doctors choose surgical routes by considering not only the patient's health status, but also the psychological needs of patient and the patient quality of life after surgery. However the choice between vaginal, laparoscopic or abdominal routes remains controversial.

Extensive studies have been performed to compare different hysterectomies. A comprehensive and systematic review compared $\mathrm{AH}$ and $\mathrm{VH}$ with laparoscopic hysterectomy, and assessed their potential beneficial and adverse effects in women with benign gynaecological conditions ${ }^{23}$. Compared with $\mathrm{AH}$, the beneficial effects of $\mathrm{VH}$ included shorter time to normal activities, fewer febrile episodes or unspecified infections, shorter duration of hospital stay, lower intraoperative blood loss, and fewer wound or abdominal wall infections ${ }^{23}$.

The route of hysterectomy is guided by the surgical indication for hysterectomy, patient anatomy, data that support the selected procedure, informed patient preference, and the surgeon's expertise ${ }^{23}$. The common indications for traditional VH include good uterine activity, volume of uterus equivalent to less than 12 weeks' gestation, no history of pelvic surgery, normal adnexa, wide maternal pelvis, and no other anaesthetic or surgical contraindications ${ }^{24}$.

In this study, $\mathrm{VH}$ was performed in patients with uterine size upto14 weeks, and was associated with less operation time, less intraoperative blood loss and better postoperative outcomes compared with $\mathrm{AH}$, suggesting that $\mathrm{VH}$ is an effective treatment for patients with benign gynaecological diseases.

Mistrangelo et al. reported that $\mathrm{VH}$ was safe and effective in cases of greater uterine weight or volume ${ }^{11}$. Guvenal et al. found that VH could be performed with less morbidity, even in patients with a large, immobile uterus and previous pelvic surgery ${ }^{25}$. Falcone et al have confirmed the success of the vaginal approach in patients with these characteristics ${ }^{26}$. Another study shows the rates of urethral and bladder injuries at the time of VH were $0.88 \%$ and $1.76 \%$, respectively ${ }^{19}$. Consistent with this, in a recent large case series, the incidence of bowel injury was low in $\mathrm{VH}$ patients ${ }^{19}$. Furthermore, multiple studies shows conversion rates from the vaginal to abdominal approach have been reported to be of $0.4 \%$ in a retrospective review of 220 patients ${ }^{27-29}$. Wound infection is reported $0-2 \%$ after vaginal hysterectomy and $4-15 \%$ after abdominal hysterectomy in many previous studies ${ }^{30,31,32}$

while in this study it is found in $0 \%$ and $15 \%$ patients respectively. Incidence of paralytic ileus in different studies was from $0-1 \%$ for vaginal hysterectomy and 6-8\% for abdominal hysterectomy ${ }^{31,33,34}$ while in this study, it was $0 \%$ and $5.26 \%$ respectively. Vaginal vault hematoma/infection was the only complication which was found more in vaginal hysterectomy $(7.89 \%)$ patients compared to abdominal hysterectomy (2.63\%) as also found in many national and international studies. Deshpande $\mathrm{H}$ et al ${ }^{35}$ noted vaginal vault hematoma/infection in $11 \%$ for vaginal hysterectomy and $7 \%$ for abdominal hysterectomy. Miskry $\mathrm{T}$ et $\mathrm{al}^{36}$ reported its incidence as $27 \%$ and $11.1 \%$ respectively while Bharatnur $\mathrm{S}$ et al ${ }^{37}$ has found this difference as $44 \%$ and $24 \%$ respectively which is much higher than this study (7.89\%) and previous studies. Considering all these studies including the present one indicate that $\mathrm{VH}$ is a safe and effective surgical treatment for benign gynaecological diseases.

\section{Conclusion}

Vaginal hysterectomy rather than abdominal hysterectomy reduces the morbidity and length of hospital stay; and will result in considerable savings in medical care costs. Thus vaginal hysterectomy should be encouraged as much as it is feasible and possible for the patient's benefit. 


\section{Acknowledgement}

It is our great pleasure to acknowledge with heartiest gratitude the constant encouragement and guidance given us by Dr. S. M. Sirajul Islam, Director, Sher-E-Bangla Medical College \& Hospital, Barisal; Ethical Committee, Sher-E-Bangla Medical College \& Hospital, Barisal and all the patients which paved our way and acted as source of inspiration in preparing this article.

\section{References}

[1]. Michail S. Papadopoulos, Athanasios C. Tolikas, and Dimosthenis E. Miliaras. Hysterectomy-Current Methods and Alternatives for Benign Indications. Obstetrics and Gynecology International Volume 2010 (2010), Article ID 356740, 10 pages http://dx.doi.org/10.1155/2010/356740.

[2]. Edozien LC. Hysterectomy for benign conditions. BMJ 2005;330(7506):1457-8.

[3]. Kovac SR. Transvaginal hysterectomy: rationale and surgical approach. Obstet Gynecol 2004; 103:1321-5

[4]. Spilsbury K, Hammond I, Bulsara M, Semmens JB. Morbidity outcomes of 78,577 hysterectomies for benign reasons over 23 years. BJOG 2008; 115:1473-83

[5]. Silva-Filho AL, Werneck RA, de Magalhães RS, Belo AV, Triginelli SA. Abdominal vs vaginal hysterectomy: a comparative study of the postoperative quality of life and satisfaction. Arch Gynecol Obstet. 2006; 274:21-4.

[6]. Shahida A. Short and long term complications of Abdominal and Vaginal Hysterectomy for benign disease. Pak Armed Forces Med J 2004;54(1):71-5

[7]. Merrill RM. Hysterectomy surveillance in the United States, 1997 through 2005. Med Sci Monit 2008;14(1):CR24-CR31.

[8]. Saha R, Sharma M, Padhye S, Karki U, Pandey S, Thapa J. Hysterectomy: an analysis of perioperative and post operative complication. Kathmandu Univ Med J 2003:1:124-7.

[9]. Milovanović Z, Stanojević D. [Myomectomy via the vagina]. Srp Arh Celok Lek 2004;132(1-2):18-21

[10]. Carminati R, Ragusa A, Giannice R, Pantano F. Anterior and posterior vaginal myomectomy: a new surgical technique. Med Gen Med 2006;8(1):42

[11]. Mistrangelo E, Febo G, Ferrero B, Ferrero S, Deltetto F, Camanni M. Safety and efficacy of vaginal hysterectomy in the large uterus with the LigaSure ${ }^{\mathrm{TM}}$ bipolar diathermy system. Am J Obstet Gynecol.2008;199(5):475.e1-5. doi: 10.1016/j.ajog.2008.03.025. [PubMed]

[12]. Farrell E. Dysfunctional uterine bleeding. Aust Fam Physician 2004; 33:906-8.

[13]. Leung KY. Changing pattern of hysterectomies for benign conditions. Hong Kong Med J 2007; 13(3):176-7.

[14]. Harris WJ. Early complications of abdominal and vaginal hysterectomy. Obstet Gynecol Surv 1995; 50: 795-805.

[15]. Dutton S, Hirst A, McPherson K, Nicholson T, Maresh MA. UK multicentre retrospective cohort study comparing hysterectomy and uterine artery embolisation for the treatment of symptomatic uterine fibroids (HOPEFUL Study): main results on medium-term safety and efficacy. BJOG 2007; 114(11):1340-51.

[16]. McCracken G, Hunter D, Morgan D, Price JH. Comparison of laparoscopic-assisted vaginal hysterectomy, total abdominal hysterectomy and vaginal hysterectomy. Ulster Med J 2006; 75(1):54-8.

[17]. Wu HH, Yang PY, Yeh GP, Chou PH, Hsu JC, Lin KC. The detection of ureteral injuries after hysterectomy. J Minim Invasive Gynecol 2006; 13:403-8.

[18]. Cosson M, Lambaudie E, Boukerrou M, Querleu D, Crépin G. Vaginal, laparoscopic, or abdominal hysterectomies for benign disorders: immediate and early postoperative complications. Eur J Obstet Gynecol Reprod Biol 2001; 98:231-6.

[19]. Ibeanu OA, Chesson RR, Echols KT, Nieves M, Busangu F, Nolan TE. Urinary tract injury during hysterectomy based on universal cystoscopy. Obstet Gynecol. 2009;113(1):6-10.doi: 10.1097/AOG.0b013e31818f6219. [PubMed]

[20]. McPherson K, Metcalfe MA, Herbert A, Maresh M, Casbard A, Hargreaves J, Bridgman S, Clarke A. Severe complications of hysterectomy: the VALUE study. BJOG 2004; 111:688-94.

[21]. McPherson K, Herbert A, Judge A, Clarke A, Bridgman S, Maresh M, Overton C. Psychosexual health 5 years after hysterectomy: population-based comparison with endometrial ablation for dysfunctional uterine bleeding. Health Expect 2005; 8:234-43.

[22]. Kulkarni MM, Rogers RG. Vaginal hysterectomy for benign disease without prolapse. Clin Obstet Gynecol.2010; 53:5-16. [PubMed]

[23]. Nieboer TE, Johnson N, Lethaby A, Tavender E, Curr E, Garry R, et al. Surgical approach to hysterectomy for benign gynaecological disease. Cochrane Database Syst Rev. 2009;(3):CD003677. doi: 10.1002/14651858.CD003677.pub4. [PubMed]

[24]. Bing Chen, Dong-Ping Ren, Jing-Xuan Li, and Chun-Dong Li. Comparison of vaginal and abdominal hysterectomy:A prospective nonrandomized trial. Pak J Med Sci. 2014 Jul-Aug; 30(4): 875-879.

[25]. Guvenal T, Ozsoy AZ, Kilcik MA, Yanik A. The availability of vaginal hysterectomy in benign gynaecological diseases: a prospective, non-randomized trial. J Obstet Gynaecol Res. 2010;36(4):832-837. doi: 10.1111/j.1447-0756.2010.01183.x. [PubMed]

[26]. Falcone T, Walters MD. Hysterectomy for benign disease. Obstet Gynecol. 2008;111:753-767. [PubMed]

[27]. Kafy S, Huang JY, Al-Sunaidi M, Wiener D, Tulandi T. Audit of morbidity and mortality rates of 1792 hysterectomies. J Minim Invasive Gynecol. 2006;13(1):55-59. [PubMed]

[28]. Levy B, Emery L. Randomized trial of suture versus electrosurgical bipolar vessel sealing in vaginal hysterectomy. Obstet Gynecol. 2003;102:147-151. [PubMed]

[29]. Kriplani A, Garg P, Sharma M, Lal S, Agarwal N. A review of total laparoscopic hysterectomy using LigaSure ${ }^{\mathrm{TM}}$ uterine artery-sealing device: AIIMS experience. J Laparoendosc Adv Surg Tech A.2008;18(6):825-829. doi: 10.1089/lap.2008.0034. [PubMed]

[30]. Dawood NS, Mahmood R, Haseeb N. Comparison of vaginal and abdominal hysterectomy: peri- and post-operative outcome. J Ayub Med Coll Abbott. 2009;21(4):116-20.

[31]. Iftikhar R. Vaginal hysterectomy is superior than abdominal hysterectomy. J Surg Pak (International). 2008;13(2):55-8.

[32]. Kayastha S, Tuladhar H. Vaginal hysterectomy vs abdominal hysterectomy. Nepal Med Coll J. 2006;8(4):259-62

[33]. Ikram M, Saeed Z, Saeed R, Saeed M. Abdominal versusvaginal hysterectomy. Professional Med J. 2008;15:486-91

[34]. Schindlbeck C, Klauser K, Dian D, Janni W, Friese K.Comparison of total laparoscopic, vaginal and abdominalhysterectomy. Arch Gynecol Obstet. 2008;277:331-7.

[35]. Deshpande H, Puri M, Dahiya P.A clinical study of vault hematomas after different types ofhysterectomies. Int J Pharm Biomed Sci. 2013;4(3):91-5

[36]. MiskryT, Magos A. Randomized prospective double-blind comparison of abdominal versus vaginal hysterectomy in women without uterovaginal prolapse. ActaObstet Gynecol. 2003;82:351-58.

[37]. Bharatnur S. Comparative study of abdominal versus vaginalhysterectomy in Non-Descent cases. Internet J Gynaecol Obstet.2011;15(2):1528-8439 